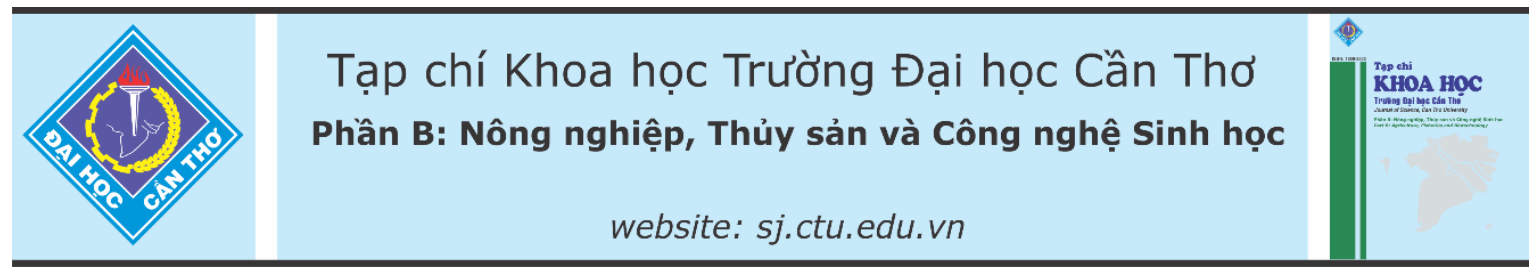

DOI:10.22144/ctu.jvn.2021.094

\title{
XÁC ĐỊNH ĐẶC TÍNH HÌNH THÁI VÀ HÓA HỌC PHẪU DIỆN ĐÂT PHÈN NHIỄM MẠN CỦA Hệ THỐNG CANH TÁC LÚÁ-TÔM TẠI XÃ LộC NINH, HUYỆN HỐNG DÂN, TỈNH BẠC LIÊU
}

\author{
Nguyễn Quốc Khương ${ }^{1 *}$, Lê Vĩnh Thúc ${ }^{1}$, Nguyễn Minh Phụng ${ }^{1}$, Phan Chí Nguyện ${ }^{2}$, \\ Trần Ngọc Hữu ${ }^{1}$ và Lý Ngọc Thanh Xuân ${ }^{3}$ \\ ${ }^{1}$ Bộ môn Khoa học cây trồng, Khoa Nông nghiệp, Truờng Đại học Cần Tho' \\ ${ }^{2}$ Khoa Môi truò̀ng và Tài nguyên Thiên nhiên, Truờng Đại học Cần Tho \\ ${ }^{3}$ Truò̀ng Đại học An Giang, Đại học Quốc gia thành phố Hồ Chí Minh \\ *Người chịu trách nhiệm về bài viết: Nguyê̂n Quốc Khuonng (email: nqkhuong@ctu.edu.vn)
}

\section{Thông tin chung:}

Ngày nhận bài: $28 / 10 / 2020$

Ngày nhân bài sủa: 16/12/2020

Ngày duyệt đăng: 25/06/2021

Title:

Investigation of morphological and chemical properties of soil profile in rice-shrimp system in Ninh Hoa commune, Hong Dan district, Bac Lieu province

\section{Tùr khóa:}

Đất phèn nhiễm mặn, lúa-tôm, hóa học đất, hình thái đất, phẫu diện đất

\section{Keywords:}

Acid sulfate soil, rice-shrimp system, soil profile, soil chemistry, soil morphology

\section{ABSTRACT}

The objective of this study was to determine the morphological and chemical properties of soil profile in rice-shrimp system. Soil morphological characteristics were directly described by Munsell color chart in the field in Loc Ninh commune, Hong Dan district, Bac Lieu province. Soil samples were collected based on original horizons to analyze the chemical parameters. The results showed that soil profile as $H D-L N-01$ was classified as potential acid sulfate soil-sodium contamination, with deep presence of sulfidic materials while profiles $H D-L N-02$ and $H D-L N-03$ were named active acid sulfate soil, sodium contamination with deep presence of sulfidic materials. For soil chemistry parameters, $\mathrm{pH}_{\mathrm{KCl}}$ of surface soil was lower than 4.50 at ratio of soil: extraction liquid 1:5. Moreover, total nitrogen was evaluated at low threshold, and concentration of available ammonium in top soil layer was 3.98-9.07 $\mathrm{mg} \mathrm{NH}_{4}^{+} \mathrm{kg}^{-1}$. Total phosphorus content was assessed at low level, concentration of soluble phosphorus in top soil layer was 1.93-8.34 $\mathrm{mg} \mathrm{P} \mathrm{kg}^{-1}$. Besides, soil phosphorus fractions of aluminum phosphorus, ferrous phosphorus and calcium phosphorus were evaluated at the high concentration. Moreover, exchangeable sodium content was determined 4.17-4.99 meq $\mathrm{Na}^{+} 100 \mathrm{~g}^{-1}$ while organic matter was assessed in ranging of very low to low level.

\section{TÓM TẮT}

Mục tiêu của nghiên cúu đánh giá đặc tính hình thái và hóa học của phẫu diện đất phèn nhiễm mặn ở hệ thống canh tác lúa-tôm. Mô tả đặc tính hình thái dưa trên bảng so màu Munsell đối với ba phẫu diện của xã Lộc Ninh, huyện Hồng Dân, tỉnh Bạc Liêu. Thu mẫu đất theo tầng phát sinh trên ba phẫu diện canh tác lúa-tôm để phân tích đặc tính hóa học đất. Kết quả hình thái cho thấy phẫu diện đất HD-LN-01 thuộc đất phèn tiềm tàng xuất hiện rất sâu, nhiễm mặn trong khi phẫu diện đất HD-LN-02 và HD-LN-03 được phân loại là đất phèn hoạt động xuất hiện sâu, nhiễm mặn. Đối với đặc tính hóa hoc, giá trị $\mathrm{H}_{\mathrm{KCl}}$ tầng đất mặt nhỏ hơn 4,50. Hàm lương đạm tổng số ở đất tầng mặt được đánh giá ở mưc thấp, lượng đạm hưu dụng dao động 3,98-9,07 $m g \mathrm{NH}_{4}{ }^{+} \mathrm{kg}^{-1}$. Hàm lương tổng số được đánh giá ở múc nghèo, với hàm lương lân dễ tiêu ở đất tầng mặt 1,93-8,34 mg P kg-1. Ngoài ra, hàm luợng lân khó tan gồm lân nhôm, lân sắt và lân calcium cao. Hàm luợng $\mathrm{Na}^{+}$trao đổi dao động 4,17-4,99 meq $\mathrm{Na}^{+} 100 \mathrm{~g}^{-1}$ đất. Hàm lương chất hưu co được đánh giá ở mức rất thấp đến thấp. 


\section{MỞ ĐẦU}

Mô hình lúa tôm phù hợp với điều kiện tự nhiên của các vùng nước lợ vì trồng lúa vào mùa mưa và sử dụng cánh đồng lúa để nuôi tôm vào mùa nắng, thời điểm độ mặn quá cao cho canh tác lúa. Chính phủ Việt Nam khuyến khích phát triển mô hình này vào năm 2001 , với tổng diện tích của mô hình canh tác lúa-tôm vào năm 2000 là 71.000 ha lên 153.000 ha vào năm 2014 (Grassi et al., 2017) và dự đoán đến năm 2030 khoảng 230.000 ha (Tuan et al., 2016). So với hệ thống canh tác lúa-lúa, mô hình lúa-tôm góp phần cải thiện thu nhập của người dân ở Đồng bằng sông Cửu Long (ĐBSCL) (Be et al., 1999; Grassi et al., 2017). Ngoài ra, việc sử dụng các hợp chất giảm mặn như vôi đã làm thay đổi nồng độ các cation trong đất (Lê Văn Dang \& Ngô Ngọc Hưng, 2018). Việc ngập mặn kéo dài có thể dẫn đến hiện tượng sodic hóa, tuy nhiên, hiện tượng này chưa xảy ra đối với đất trong hệ thống canh tác lúa tôm ở ĐBSCL (Tho et al., 2008). Kết quả phân tích ở vùng bán đảo $\mathrm{Cà} \mathrm{Mau} \mathrm{gồm} \mathrm{Bạc}$ Liêu và $\mathrm{Cà} \mathrm{Mau}$ cũng đạt kết quả tương tự (Nguyễ் Quốc Khương \& Ngô Ngọc Hưng, 2015a; 2015b). Do đó, các biện pháp này có thể làm thay đổi đặc tính hình thái và hóa học đất. Vì vậy, nghiên cứu được thực hiện nhằm xác định đặc tính hình thái và đặc tính hóa học đất của mô hình lúa-tôm tại xã Lộc Ninh, huyện Hồng Dân, tỉnh Bạc Liêu.

\section{PHƯƠNG TIỆN VÀ PHƯƠNG PHÁP}

\subsection{Phương tiện}

Địa điểm và thời gian: Nghiên cứu được thực hiện tại vùng đất nhiễm mặn canh tác lúa-tôm ở xã Lộc Ninh, huyện Hồng Dân, tỉnh Bạc Liêu vào tháng 7/2019.

Hiện trạng vào thời điểm thu mẫu: Giai đoạn ngập sau khi kết thúc vụ lúa để chuẩn bị cho nuôi vụ tôm.

Dụng cư: Khoan có độ sâu $2 \mathrm{~m}$, bảng so màu Munsel, giấy đo $\mathrm{pH}$ và dung dịch $\mathrm{H}_{2} \mathrm{O}_{2}$.

Chỉ tiêu theo dõi: Các đặc tính hóa học đất được xác định gồm $\mathrm{pH}$ (đất: chất trích là $1: 5$ với chất trích là $\mathrm{H}_{2} \mathrm{O}$ hay $\left.\mathrm{KCl}\right), \mathrm{EC}$, chất hữu cơ, $\mathrm{N}_{\text {tổng số, đạm hữu }}$ dụng dạng $\mathrm{NH}_{4}{ }^{+}, \mathrm{P}_{\text {tổng số, }} \mathrm{P}_{\text {dễ tiêu}}$, các thành phần lân bao gồm Al-P, Fe-P, Ca-P, khả năng trao đổi cation (CEC), các cation trao đổi $\left(\mathrm{K}^{+}, \mathrm{Na}^{+}, \mathrm{Ca}^{2+}, \mathrm{Mg}^{2+}\right)$.

\subsection{Phương pháp}

Phuơng pháp mô tả đặc tính hình thái đất: Phương pháp mô tả phẫu diện đất được thực hiện theo phương pháp của $\mathrm{FAO}$ (1977) bằng cách khoan phẫu diện đất đến độ sâu $2 \mathrm{~m}$ để xác định các đặc tính hình thái dựa trên bảng so màu Munsel.

Phuong pháp phân loại đất: Phân loại đất theo hệ thống phân loại của Schad and Spaargaren (2006) từ tầng chẩn đoán và đặc tính chẩn đoán.

Phuoong pháp thu mẫu đất và xử lý mẫu đất: Mẫu đất được thu theo tầng phát sinh để phân tích các đặc tính hóa học. Mỗi tầng đất thu khoảng $500 \mathrm{~g}$, mang về phòng thí nghiệm. Đất được phơi khô tự nhiên trước khi nghiền qua rây có kích thước 0,5 và 2,0 $\mathrm{mm}$.

Phưong pháp phân tích mẫu đất: Theo Bremner and Sparks (1996), các phương pháp phân tích được tóm tắt như sau. $\mathrm{pH}_{\mathrm{H} 2 \mathrm{O}}$ hoặc $\mathrm{pH}_{\mathrm{KCl}}$ được trích tỷ lệ đất: $\mathrm{H}_{2} \mathrm{O}$ hoặc đất: $\mathrm{KCl} 1 \mathrm{M}$ (tî̉ lệ 1:5), sau đó dung dịch trích được đo bằng $\mathrm{pH}$ kế. Dung dịch trích đo $\mathrm{pH}_{\mathrm{H} 2 \mathrm{O}}$ được sử dụng để đo $\mathrm{EC}$ bằng $\mathrm{EC}$ kế. Đạm tổng số được vô cơ hóa bằng hỗn hợp $\mathrm{H}_{2} \mathrm{SO}_{4(\text { (đ) }}$ $\mathrm{CuSO}_{4}-\mathrm{Se}$, tỉ lệ:100-10-1 và xác định bằng phương pháp chưng cất Kjeldahl. Đạm hữu dụng được xác định bằng phương pháp phenol blue ở bước sóng $640 \mathrm{~nm}$. Lân tổng số được chuyển sang dạng vô cơ bằng hợp chất $\mathrm{H}_{2} \mathrm{SO}_{4 \text { (đđ) }}-\mathrm{HClO}_{4}$, để hiện màu ascorbic acid ở bước sóng $880 \mathrm{~nm}$. Thành phần lân trong đất gồm lân sắt, lân nhôm và lân calcium được trích bằng các hợp chất theo thứ tự sau $\mathrm{NaOH} 0,1$ $\mathrm{M}, \mathrm{NH}_{4} \mathrm{~F} 0,5 \mathrm{M}$ và $\mathrm{H}_{2} \mathrm{SO}_{4} 0,25 \mathrm{M}$. Lân dễ tiêu (Bray II) được xác định bằng phương pháp trích đất với hỗn hợp $0,1 \mathrm{~N} \mathrm{HCl}+0,03 \mathrm{~N} \mathrm{NH}_{4} \mathrm{~F}$, tỉ lệ đất:nước bằng 1:7. Chất hữu cơ được đo theo phương pháp Walkley-Black, oxy hoá bằng $\mathrm{H}_{2} \mathrm{SO}_{4(\text { (đđ) }}-\mathrm{K}_{2} \mathrm{Cr}_{2} \mathrm{O}_{7}$ trước khi chuẩn độ bằng $\mathrm{FeSO}_{4}$. Khả năng trao đổi cation $(\mathrm{CEC})$ được trích bằng $\mathrm{BaCl}_{2} 0,1 \mathrm{M}$, chuẩn độ với EDTA $0,01 \mathrm{M}$. Hàm lượng $\mathrm{K}^{+}, \mathrm{Na}^{+}, \mathrm{Ca}^{2+}$ và $\mathrm{Mg}^{2+}$ từ dung dịch trích $\mathrm{CEC}$ được xác định trên máy quang phổ hấp thu nguyên tử.

Thang đánh giá: Các đặc tính đất được đánh giá dựa vào Bảng 1 . 
Bảng 1. Thang đánh giá đặc tính đất

\begin{tabular}{|c|c|c|c|c|c|c|c|c|c|}
\hline \multirow{2}{*}{ Giá trị } & pH (1) & CEC (2) & $\mathrm{K}^{+}(\mathbf{1})$ & $\mathrm{Ca}^{2+}(3)$ & $\mathrm{Mg}^{2+}(1)$ & $\mathbf{N}_{\text {Tổng số }}$ (4) & $\mathbf{P}_{\text {Tổng số }}(5)$ & $\mathbf{P}_{\text {Dễ tiêu }}(\mathbf{1})$ & CHC (4) \\
\hline & - & \multicolumn{4}{|c|}{ (meq $100 \mathrm{~g}^{-1}$ đất) } & $(\%)$ & $(\%)$ & $\left(\mathrm{mg} \mathrm{P} \mathrm{kg}^{-1}\right)$ & $(\% \mathrm{C})$ \\
\hline Rất thấp & $<5,1$ & $<5,0$ & - & - & - & $<0,1$ & - & - & $<2$ \\
\hline Thấp & $5,2-6,0$ & $5-15$ & $<0,4$ & $<5$ & $<0,5$ & $0,1-0,2$ & $<0,06$ & $<20$ & $2-4$ \\
\hline Trung bình & $6,1-6,5$ & $15-25$ & $0,4-0,6$ & $5-10$ & $0,5-2,5$ & $0,2-0,5$ & $0,06-0,10$ & $20-40$ & $4-10$ \\
\hline $\mathrm{Cao}$ & $6,6-7,3$ & $25-40$ & $0,6-2,0$ & $>10$ & $>2,5$ & $0,5-1,0$ & $>0,10$ & $40-100$ & $10-20$ \\
\hline Rất cao & $7,4-8,4$ & $>40$ & $>2,0$ & - & 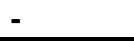 & $>1,0$ & - & $>100$ & $>20$ \\
\hline
\end{tabular}

Ghi chú:

(1) Thang đánh giá của Horneck et al. (2011);

(2) Thang đánh giá của Landon (1984);

(3) Thang đánh giá của Metson (1961);

(4) Thang đánh giá của Nguyễn Xuân Cư (2000);

\section{KẾT QUẢ VÀ THẢO LUẬN}

3.1. Đặc tính hình thái đất của phẫu diện đất phèn nhiễm mặn trong hệ thống canh tác lúa-tôm tại xã Lộc Ninh

\subsubsection{Phẫu diện đất phèn nhiễm mặn của mô hinh canh tác lúa-tôm HD-LN-O1}

Hiện trạng canh tác vào thời điểm thu mẫu của phẫu diện đất HD-LN-01 là giai đoạn ngập sau khi kết thúc vụ lúa để chuẩn bị cho vụ tôm. Phẫu diện đất thuộc biểu loại đất phèn tiềm tàng xuất hiện rất sâu, nhiễm mặn, có tầng mollic, Mollic Hypo Sali Gleysols (Bathy Proto Thionic), với ký hiệu Glwsmo (dtip). Phẫu diện đất có xuất hiện đốm rỉ ở độ sâu 35-130 cm. Mẫu đất được phân chia thành bốn tầng chính, với đặc tính được mô tả chi tiết ở Bảng 2.

Bảng 2. Đặc điểm hình thái của phẫu diện đất phèn nhiễm mặn trong hệ thống canh tác lúa-tôm HDLN-01 tại xã Lộc Ninh, huyện Hồng Dân, tỉnh Bạc Liểu

\begin{tabular}{|c|c|c|}
\hline $\begin{array}{l}\text { Ký hiệu } \\
\text { tầng đất }\end{array}$ & Độ sâu (cm) & $\begin{array}{l}\text { Đặc điểm hình thái của phẫu diện đất phèn nhiễm mặn trong mô hình canh } \\
\text { tác lúa-tôm HD-LN-01 tại xã Lộc Ninh, huyện Hồng Dân, tỉnh Bạc Liêu }\end{array}$ \\
\hline Ap & $0-35$ & $\begin{array}{l}\text { Đất có nền màu xám xanh rất đậm (Gley } 23 / 10 \mathrm{~B}) \text {; sét pha thịt; ầm; tính dẻo dính } \\
\text { trung bình; bán thuần thục }(\mathrm{r}) \text { đến thuần thục }(\mathrm{R}) \text {; rề thực vật trung bình ở dạng } \\
\text { tươi, chất hữu cơ ít ở dạng phân hủy và khuếch tán trong nền đất; tầng đất chuyển } \\
\text { tầng rõ bởi màu nền và màu đốm rỉ, gợn sóng xuống tầng. }\end{array}$ \\
\hline $\mathrm{Bg} 1$ & $35-90$ & $\begin{array}{l}\text { Tầng đất có màu nền xám xanh nhạt (Gley } 17 / \mathrm{N}) \text {; sét; ẩm; tính dẻo dính cao; thuần } \\
\text { thục }(\mathrm{R}) \text {; tầng đất có đốm rỉ màu vàng }(2.5 \mathrm{Y} 7 / 8) \text { và màu đỏ ( } 10 \mathrm{R} 4 / 8) \text {, đốm rî̀ } \\
\text { chiếm khoảng } 9-10 \% \text { và đốm có dạng ồ và dạng ống rễ; tầng đất chuyê̂n tầng từ } \\
\text { từ, phẳng xuông tầng. }\end{array}$ \\
\hline $\mathrm{Bg} 2$ & $90-130$ & $\begin{array}{l}\text { Màu nền của tầng đất là màu xám (5Y 5/1); sét; ẩm; tính dẻo dính cao, thuần thục } \\
\text { (R); tầng đất có đốm rỉ màu nâu ( } 7.5 \text { YR 4/4) và màu nâu ô liu ( } 2.5 \mathrm{Y} 4 / 4) \text {, đốm rỉ } \\
\text { phân bố khoảng } 1-2 \% \text { và ở dạng ống rễ; tầng đất chuyển tầng rõ bởi sự kết thúc } \\
\text { của đốm, phẳng xuông tầng. }\end{array}$ \\
\hline $\mathrm{Cr}$ & $130-200$ & $\begin{array}{l}\text { Đất có màu nền là màu xám }(5 \mathrm{Y} 6 / 1) \text {; sét; ẩm; dẻo và dính trung bình; bán thuần } \\
\text { thục (r) đến thuần thục }(\mathrm{R}) \text {; có ít tế khổng } 2-3 \mathrm{~mm} \text {, tầng đất có độ } \mathrm{pH}_{\mathrm{H} 2 \mathrm{O} 2} \leq 2,0 \text {, } \\
\text { chứa vật liệu sinh phèn pyrite. }\end{array}$ \\
\hline
\end{tabular}

\subsubsection{Phẫu diện đất phèn nhiễm mặn của mô hinh canh tác lúa-tôm HD-LN-02}

Phẫu diện đất có ký hiệu HD-LN-02 có hiện trạng canh tác là đất sau vụ lúa. Phẫu diện đất được phân loại là đất phèn hoạt động xuất hiện sâu, nhiểm mặn, có tầng mollic, Mollic Hypo Sali Gleysols (Endo Ortho Thionic), được đặt tên theo ký hiệu là Glwsmo(ntio). Đất có đốm jarosite xuất hiện ở độ sâu $90-130 \mathrm{~cm}$. Phẫu diện đất được phân chia thành bốn tầng chính dựa trên tầng phát sinh (Bảng 3). 
Bảng 3. Đặc điểm hình thái của phẫu diện đất phèn nhiễm mặn trong hệ thống canh tác lúa-tôm HDLN-02 tại xã Lộc Ninh, huyện Hồng Dân, tỉnh Bạc Liêu

\begin{tabular}{|c|c|c|}
\hline $\begin{array}{l}\text { Ký hiệu } \\
\text { tầng đất }\end{array}$ & $\begin{array}{c}\text { Độ sâu } \\
\text { (cm) }\end{array}$ & $\begin{array}{l}\text { Đặc điểm hình thái của phẫu diện đất phèn nhiễm mặn trong mô hình canh tác lúa-tôm } \\
\text { HD-LN-02 tại xã Lộc Ninh, huyện Hồng Dân, tỉnh Bạc Liêu }\end{array}$ \\
\hline Ap & $0-55$ & $\begin{array}{l}\text { Đất có nền màu xanh đen (Gley } 22.5 / 5 \mathrm{~PB}) \text {; sét pha; ẩm; tính dẻo và dính trung bình; bán thuần } \\
\text { thục }(\mathrm{r}) \text { đến thuần thục }(\mathrm{R}) \text {; tầng đât có chứa rề thực vật từ ít đến trung bình và tươi; chất hữu } \\
\text { cơ nhiều trong tình trang bán phân hủy và phân hủy, chất hữu cơ phân hủy được khuếch tán } \\
\text { trong nền đất; chuyển tầng rỏ bởi sự xuất hiện của đốm, gợn sóng xuống tầng. }\end{array}$ \\
\hline $\mathrm{Bg}$ & $55-90$ & $\begin{array}{l}\text { Đất có nền màu xám xanh nhạt (Gley } 17 / \mathrm{N}) \text {; sét; ầm; tính dẻo và dính cao; thuần thục }(\mathrm{R}) \text {; } \\
\text { tầng đất có xuất hiện đốm rỉ màu nâu đỏ sâ̂m (5YR } 3 / 4) \text { và màu nâu ô liu nhạt }(2.5 \mathrm{Y} 5 / 6) \text {, với } \\
\text { mật độ phân bố khoảng } 2 \% \text { và đốm rỉ có dạng rễ; chuyển tầng rõ bởi màu nền và màu đốm } \\
\text { jarosite, phẳng xuống tầng. }\end{array}$ \\
\hline Bgj & $90-130$ & 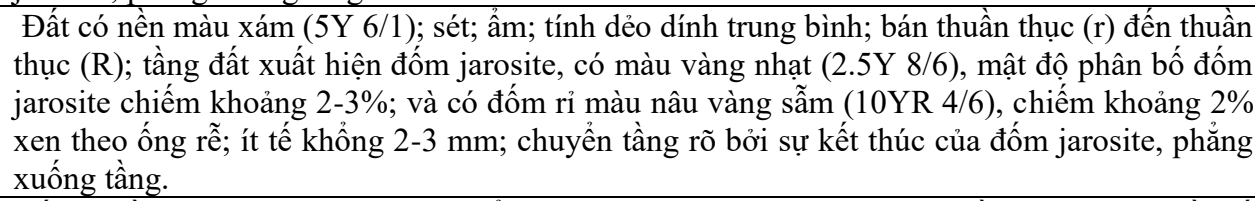 \\
\hline & & xám (5Y 5/1); sét; ẩm; tính dẻo và dính tr \\
\hline
\end{tabular}

3.1.3. Phẫu diện đất phèn nhiễm mặn của mô hình canh tác lúa-tôm $H D-L N-03$

Hiện trạng vào thời điểm thu mẫu của phẫu diện đất HD-LN-02 là đất lúa-tôm và đang trong quá trình ngập nước. Phẫu diện đất thuộc biểu loại phèn hoạt động xuất hiện sâu, nhiễm mặn, có tầng mollic, Mollic Hypo Sali Gleysols (Endo Ortho Thionic), với tên gọi Glwsmo(ntio). Phẫu diện đất xuất hiện đốm jarosite ở độ sâu $65-95 \mathrm{~cm}$. Dựa trên tầng phát sinh, phẫu diện đất được chia thành năm tầng chính (Bảng 4).

Bảng 4. Đặc điểm hình thái của phẫu diện đất phèn nhiễm mặn trong hệ thống canh tác lúa-tôm HDLN-03 tại xã Lộc Ninh, huyện Hồng Dân, tỉnh Bạc Liêu

\section{Ký hiệu Độ sâu Đặc điểm hình thái của phẫu diện đất phèn nhiễm mặn trong mô hình canh tác lúa-} tầng đất $(\mathrm{cm})$ tôm HD-LN-03 tại xã Lộc Ninh, huyện Hồng Dân, tỉnh Bạc Liêu

\begin{tabular}{|c|c|c|}
\hline Ap & $0-25$ & $\begin{array}{l}\text { Đất có nền màu xanh đen (Gley } 22.5 / 5 \mathrm{~PB}) \text {; thịt pha; ẩm; tính dẻo dính trung bình; bán thuần } \\
\text { thục (r); tầng đất chứa ít rễ thực vật, tươi; chất hữu cơ nhiều ở dạng phân hủy và khuếch tán } \\
\text { trong nền đất; chuyền tầng rô bời sự xuất hiện của màu nền đất, gợn sóng xuống tầng. }\end{array}$ \\
\hline $\mathrm{Bg}$ & $25-65$ & $\begin{array}{l}\text { phân bố khoảng 3-5\% và có } \\
\text { ng. }\end{array}$ \\
\hline $\mathrm{Bgj}$ & $65-95$ & $\begin{array}{l}\text { Đất có nền màu xám xanh (Gley } 26 / 5 \mathrm{~PB}) \text {; sét; ẩm; tính dẻo và dính trung bình; thuần thục } \\
\text { (R); tầng đất xuất hiện đốm jarosite màu vàng nhạt }(2.5 \mathrm{Y} 8 / 6) \text { với mật độ chiếm khoảng } 3 \% \text {, } \\
\text { đốm jarosite ở dạng ống rế; và xen lẫn đốm rỉ màu nâu đỏ ( } 2.5 \mathrm{YR} 4 / 8) \text {, chiếm khoảng } 2 \% \\
\text { và đốm rỉ có dạng đốm; nhiều tế khổng } 5-10 \mathrm{~mm} \text {, mở, liên tục; tầng đất chuyển tầng rỏ bởi } \\
\text { màu đốm và màu nền tầng đất, phằng xuống tầng. }\end{array}$ \\
\hline $\mathrm{Cr} 1$ & $95-135$ & $\begin{array}{l}\text {; tính dẻo và dính trung bình; thuần thục } \\
\text { ó pH } \mathrm{H}_{\mathrm{H} 2 \mathrm{O} 2} \leq 2,0 \text {, tầng đẩt có chứa vất liệu } \\
\text { lất hiện của đốm rỉ, phẳng xuống tầng. }\end{array}$ \\
\hline & & ẩm; tính dẻo và dính trung bình; thuần thục $(\mathrm{R})$; có \\
\hline
\end{tabular}

\section{2. Đặc tính hóa học của các phẫu diện đất phèn nhiễm mặn ở mô hình lúa-tôm}

3.2.1. . Đặc tính hóa học của phẫu diện đất phèn nhiễm mặn HD-LN-01 ở mô hìn lúa-tôm

Giá trị $\mathrm{pH}_{\mathrm{H} 2 \mathrm{O}}$ dao động 2,76-5,96 và $\mathrm{pH}_{\mathrm{KCl}}$ dao động khoảng 2,44-4,48 ở các tầng đất của phẫu diện canh tác lúa-tôm HD-LN-01 tại xã Lộc Ninh, huyện Hồng Dân, tỉnh Bạc Liêu (Bảng 5) được đánh giá ở mức rất chua đối với tất cả các tầng đất của phẫu diện (Bảng 1). Giá trị EC dao động giữa các tầng đất $2,20-11,40 \mathrm{mS} \mathrm{cm}^{-1}$. Tuy nhiên, ở tầng đất có độ sâu 
từ 130 đến $200 \mathrm{~cm}$ có giá trị $\mathrm{EC}$ rất lớn, đạt 11,40 $\mathrm{mS} \mathrm{cm}{ }^{-1}$ (Bảng 5).

Hàm lượng cation trao đổi được đánh giá ở mức trung bình ở các tầng đất của phẫu diện HD-LN-01 theo thang đánh giá ở Bảng 1 , với hàm lượng 5,10 $8,35 \mathrm{meq} 100 \mathrm{~g}^{-1}$ đất (Bảng 5 ). Đối với hàm lượng $\mathrm{K}^{+}, \mathrm{Na}^{+}, \mathrm{Ca}^{2+}$ và $\mathrm{Mg}^{2+}$ ở các tầng đất của phẫu diện lần lượt là $0,43-0,93$ meq $\mathrm{K}^{+} 100 \mathrm{~g}^{-1}$ đất, 3,01-4,99 meq $\mathrm{Na}^{+} 100 \mathrm{~g}^{-1}$ đất, $0,71-1,04$ meq Ca ${ }^{2+} 100 \mathrm{~g}^{-1}$ đất và $10,0-20,8$ meq $\mathrm{Mg}^{2+} 100 \mathrm{~g}^{-1}$ dất (Bảng 5). Do đó, theo thang đánh giá ở Bảng 1 hàm lượng $\mathrm{K}^{+}$được đánh giá ở mức cao từ tầng đất mặt đến $130 \mathrm{~cm}$, hàm lượng $\mathrm{Ca}^{2+}$ được đánh giá ở ngưỡng thấp và hàm lượng $\mathrm{Mg}^{2+}$ được đánh giá cao ở tất cả các tầng đất.

Bảng 5. Tính chất hóa học của phẫu diện đất phèn nhiễm mặn HD-LN-01 ở mô hình lúa-tôm

\begin{tabular}{|c|c|c|c|c|c|c|c|c|}
\hline \multirow{2}{*}{$\begin{array}{l}\text { Tầng đất } \\
(\mathrm{cm})\end{array}$} & $\mathrm{pH}_{\mathrm{H} 2 \mathrm{O}}$ & $\mathrm{pH}_{\mathrm{KCl}}$ & EC & CEC & $\mathbf{N a}^{+}$ & $\mathbf{K}^{+}$ & $\mathrm{Ca}^{2+}$ & \multirow[t]{2}{*}{$\mathrm{Mg}^{2+}$} \\
\hline & (Đất:Nước 1:5,0) & $-1: 2,5)$ & $\left(\mathrm{mS} \mathrm{cm} \mathbf{c m}^{-1}\right)$ & \multicolumn{4}{|c|}{ (meq $100 \mathrm{~g}^{-1}$ đất) } & \\
\hline $0-35$ & 5,28 & 4,43 & 3,50 & 7,37 & 4,99 & 0,93 & 1,04 & $\overline{10,0}$ \\
\hline $35-90$ & 5,38 & 3,81 & 2,20 & 5,10 & 3,01 & 0,60 & 0,71 & 10,1 \\
\hline $90-130$ & 5,96 & 4,48 & 3,20 & 8,35 & 3,01 & 0,85 & 0,84 & 20,8 \\
\hline $130-200$ & 2,76 & 2,44 & 11,40 & 8,11 & 3,99 & 0,43 & 1,01 & 18,6 \\
\hline
\end{tabular}

Hàm lượng đạm tổng số ở các tầng đất của phẫu diện trong Bảng 6 dao động 0,08-0,22\% được đánh giá ở mức thấp theo thang đánh giá ở Bảng 1 . Hàm lượng đạm hữu dụng ở tầng đất canh tác đạt $4,94 \mathrm{mg}$ $\mathrm{NH}_{4}{ }^{+} \mathrm{kg}^{-1}$, trong khi đó các tầng bên dưới đạt 6,80$8,53 \mathrm{mg} \mathrm{NH}_{4}{ }^{+} \mathrm{kg}^{-1}$ (Bảng 6).

Hàm lượng lân tổng số ở các tầng đất được đánh giá ở mức nghèo lân, dao động $0,018-0,023 \%$, theo thang đánh giá ở Bảng 1 . Tương tự, hàm lượng lân dễ tiêu ở các tầng đất đạt $1,29-19,24 \mathrm{mg} \mathrm{P} \mathrm{kg}^{-1}$ được xác định ở mức thấp theo thang đánh giá trong Bảng 1. Hàm lượng lân nhôm đạt $15,5-35,2 \mathrm{mg} \mathrm{P} \mathrm{kg}^{-1}$, lân sắt đạt $16,2-92,8 \mathrm{mg} \mathrm{P} \mathrm{kg}^{-1}$ và lân calcium đạt 23,2$111,0 \mathrm{mg} \mathrm{P} \mathrm{kg}^{-1}$ (Bảng 6).

Bảng 6: Độ phì nhiêu của phẫu diện đất phèn nhiễm mặn HD-LN-01 ở mô hình lúa-tôm

\begin{tabular}{|c|c|c|c|c|c|c|c|c|}
\hline \multirow{2}{*}{$\begin{array}{l}\text { Tầng đất } \\
(\mathrm{cm})\end{array}$} & $\mathbf{N}_{\text {Tổng số }}$ & $\mathrm{NH}_{4}{ }^{+}$ & $\overline{\mathbf{P}_{\text {Tổng số }}}$ & $\mathbf{P}_{\text {Dễ tiêu }}$ & P-Al & P-Fe & P-Ca & $\overline{\mathrm{CHC}}$ \\
\hline & $(\%)$ & $\left(\mathrm{mg} \mathrm{NH}_{4}{ }^{+} \mathrm{kg}^{-1}\right)$ & $(\%)$ & \multicolumn{4}{|c|}{$\left.(\mathrm{mg} \mathrm{P} \mathrm{kg})^{-1}\right)$} & $(\% \mathrm{C})$ \\
\hline $0-35$ & 0,15 & 4,94 & 0,021 & 3,86 & 34,3 & 16,2 & 53,9 & 2,14 \\
\hline $35-90$ & 0,22 & 8,53 & 0,021 & 1,29 & 35,2 & 65,6 & 23,2 & 0,35 \\
\hline $90-130$ & 0,20 & 8,07 & 0,018 & 7,06 & 27,1 & 45,1 & 36,0 & 0,36 \\
\hline $130-200$ & 0,08 & 6,80 & 0,023 & 19,24 & 15,5 & 92,8 & 111,0 & 1,45 \\
\hline
\end{tabular}

Theo thang đánh giá ở Bảng 1 , chất hữu cơ ở tầng đất mặt hàm lượng $2,14 \% \mathrm{C}$ được đánh giá ở mức thấp, nhưng ở các tầng bên dưới dao động từ 0,35 đến $1,45 \% \mathrm{C}$ được đánh giá ở mức rất thấp (Bảng 6).
3.2.2. Đặc tính hóa học của phẫu diện đất phèn nhiếm mặn $H D-L N-02$ ở mô hình lúa-tôm

$\mathrm{pH}_{\mathrm{H} 2 \mathrm{O}}$ đạt giá trị 2,38-5,10 ở phẫu diện đất canh tác lúa-tôm $\mathrm{HD}-\mathrm{LN}-02$. Tương tự, giá trị $\mathrm{pH}_{\mathrm{KCl}}$ đạt 2,35-3,90, được đánh giá ở mức rất chua theo thang đánh giá ở Bảng 1. Giá trị $\mathrm{EC}$ của các tầng đất dao động 3,20-12,40 mS cm-1 (Bảng 7).

Bảng 7. Tính chất hóa học của phẫu diện đất phèn nhiễm mặn HD-LN-02 ở mô hình lúa-tôm

\begin{tabular}{|c|c|c|c|c|c|c|c|c|}
\hline \multirow{2}{*}{$\begin{array}{c}\text { Tầng đất } \\
\text { (cm) }\end{array}$} & $\mathrm{pH}_{\mathrm{H} 2 \mathrm{O}}$ & $\mathrm{pH}_{\mathrm{KCl}}$ & EC & CEC & $\mathrm{Na}^{+}$ & $\mathbf{K}^{+}$ & $\mathrm{Ca}^{2+}$ & $\mathrm{Mg}^{2+}$ \\
\hline & $\begin{array}{r}\text { (Đất:Nước } \\
\sim 1: 5,0) \\
\end{array}$ & $\begin{array}{r}\text { (Đất:KCl } \\
\sim 1: 2,5) \\
\end{array}$ & $\left(\mathrm{mS} \mathrm{cm} \mathbf{c m}^{-1}\right)$ & \multicolumn{5}{|c|}{ (meq $100 \mathrm{~g}^{-1}$ đất) } \\
\hline $0-55$ & 5,10 & 3,90 & 3,50 & 8,18 & 4,17 & 0,93 & 0,97 & 9,56 \\
\hline $55-90$ & 4,20 & 3,13 & 3,20 & 7,54 & 5,81 & 0,45 & 0,69 & 10,70 \\
\hline $90-130$ & 3,01 & 2,70 & 6,90 & 8,16 & 5,12 & 0,58 & 0,55 & 12,00 \\
\hline $130-200$ & 2,38 & 2,35 & 12,40 & 7,14 & 3,42 & 0,24 & 1,20 & 14,60 \\
\hline
\end{tabular}

Hàm lượng CEC được phân loại ở mức thấp theo thang đánh giá ở Bảng 1 , với giá trị 7,14-8,18 meq $100 \mathrm{~g}^{-1}$ dất. Đối với hàm lượng các cation trao đổi được so với các thang đánh giá ở bảng 1 , hàm lượng $\mathrm{Na}^{+}$trao đổi được xác định $3,42-5,81$ meq $\mathrm{Na}^{+} 100$ $\mathrm{g}^{-1}$ đất. Hàm lượng $\mathrm{K}^{+}$trao đổi ở tầng đất $0-55 \mathrm{~cm}$ đạt $0,93 \mathrm{meq} \mathrm{K}^{+} 100 \mathrm{~g}^{-1}$ đất được đánh giá ở mức cao, ở các tầng 55-90, 90-130 cm dao động 0,450,58 meq $\mathrm{K}^{+} 100 \mathrm{~g}^{-1}$ đất được xác định ở mức trung bình và tầng $130-200 \mathrm{~cm}$ đạt 0,24 meq $\mathrm{K}^{+} 100 \mathrm{~g}^{-1}$ đất được đánh giá ở mức rất thấp. Hàm lượng $\mathrm{Ca}^{2+}$ trao đổi dao động $0,55-1,20$ meq $\mathrm{Ca}^{2+} 100 \mathrm{~g}^{-1}$ đất 
được đánh giá ở mức thấp và hàm lượng $\mathrm{Mg}^{2+}$ được đánh giá ở mức cao đối với các tầng đất và có giá trị đạt 9,56-14,60 meq $\mathrm{Mg}^{2+} 100 \mathrm{~g}^{-1}$ đất (Bảng 7).

Tầng đất từ 0 đến $130 \mathrm{~cm}$, có hàm lượng đạm tổng số dao động $0,13-0,15 \%$, ở tầng $130-200 \mathrm{~cm}$ ghi nhận $0,02 \%$, được đánh giá ở mức thấp và rất thấp, theo thứ tự, so với thang đánh giá ở Bảng 1 . Đối với hàm lượng đạm hữu dụng có giá trị 1,33$5,73 \mathrm{mg} \mathrm{NH}_{4}{ }^{+} \mathrm{kg}^{-1}$ (Bảng 8).

Bảng 1 cho thấy hàm lượng lân tổng số < $0,06 \%$ được đánh giá ở mức thấp, kết quả phân tích hàm lượng lân tổng số đối với phẫu diện đất canh tác lúa- tôm dao động 0,014-0,025\% được xác định ở ngưỡng thấp. Mặc khác, hàm lượng lân dễ tiêu trong đất đạt 1,29-19,24 mg P kg${ }^{-1}$ được đánh giá ở mức thấp. Các thành phần lân khó tan trong đất như lân nhôm, lân sắt và lân calcium $14,6-45,9,28,1-84,3$ và 19,0-78,6 $\mathrm{mg} \mathrm{P} \mathrm{kg}^{-1}$, theo thứ tự (Bảng 8).

Kết quả bảng 8 cho thấy chất hữu cơ được đánh giá ở mức rất thấp ở các tầng đất có độ sâu từ 0-130 $\mathrm{cm}(0,20-1,75 \% \mathrm{C})$. Tuy nhiên, đối với tầng đất có độ sâu 130-200 cm (3,49\%C) được đánh giá ở mức thấp theo thang đánh giá thể hiện ở Bảng 1 .

Bảng 8. Độ phì nhiêu của phẫu diện đất phèn nhiễm mặn HD-LN-02 ở mô hình lúa-tôm

\begin{tabular}{|c|c|c|c|c|c|c|c|c|}
\hline \multirow{2}{*}{$\begin{array}{l}\text { Tầng đất } \\
\text { (cm) }\end{array}$} & $\mathbf{N}_{\text {Tổng số }}$ & $\mathrm{NH}_{4}{ }^{+}$ & $\mathbf{P}_{\text {Tổng số }}$ & $\mathbf{P}_{\text {Dễ tiêu }}$ & P-Al & P-Fe & P-Ca & $\overline{\mathrm{CHC}}$ \\
\hline & $(\%)$ & $\left(\mathrm{mg} \mathrm{NH}_{4}{ }^{+} \mathrm{kg}^{-1}\right)$ & $(\%)$ & & & \multicolumn{2}{|c|}{$\left(\mathrm{mg} \mathrm{P} \mathrm{kg}^{-1}\right)$} & $(\% \mathrm{C})$ \\
\hline $0-55$ & 0,13 & 3,98 & 0,025 & 8,34 & 45,9 & 84,3 & 19,0 & 1,75 \\
\hline $55-90$ & 0,13 & 5,44 & 0,014 & 1,29 & 17,3 & 49,4 & 19,0 & 0,40 \\
\hline $90-130$ & 0,15 & 5,73 & 0,018 & 1,93 & 14,6 & 69,0 & 25,0 & 0,20 \\
\hline $130-200$ & 0,02 & 1,33 & 0,025 & 19,24 & 15,9 & 28,1 & 78,6 & 3,49 \\
\hline
\end{tabular}

3.2.3. Đặc tính hóa hoc của phẫu diện đất phèn nhiếm mặn HD-LN-03 ở mô hình lúa-tôm

Phẫu diện canh tác lúa-tôm HD-LN-03 có giá trị 3,56-5,74 đối với $\mathrm{pH}_{\mathrm{H} 2 \mathrm{O}}$. Đối với giá trị $\mathrm{pH}_{\mathrm{KCl}}$ ở các tầng đất $0-135 \mathrm{~cm}$ đạt 3,56-4,60 được đánh giá ở mức rất chua và tầng $135-200 \mathrm{~cm}$ được đánh giá ở mức chua $(5,31)$ theo thang đánh giá ở Bảng 1 . Giá trị $\mathrm{EC}$ ở tầng đất dao động $2,30-8,00 \mathrm{mS} \mathrm{cm}^{-1}$ (Bảng 9).
Kết quả phân tích hàm lượng $\mathrm{CEC}$ được ghi nhận 5,47-8,44 meq $100 \mathrm{~g}^{-1}$ đất, ở ngưỡng thấp so với thang đánh giá ở Bảng 1 . Bên cạnh đó, hàm lượng $\mathrm{Na}^{+}$trao đổi dao động 1,17-11,26 meq $\mathrm{Na}^{+}$ $100 \mathrm{~g}^{-1}$ đất. Theo thang đánh giá ở Bảng 1 , hàm lượng $\mathrm{K}^{+}$và $\mathrm{Mg}^{2+}$ được đánh giá ở mức cao với giá trị dao động $0,56-1,18$ meq $\mathrm{K}^{+} 100 \mathrm{~g}^{-1}$ đất và $10,2-$ 15,6 meq $\mathrm{Mg}^{2+} 100 \mathrm{~g}^{-1}$ đất. Hàm lượng $\mathrm{Ca}^{2+}$ trao đổi được đánh giá ở mức thấp, dao động $0,54-1,11 \mathrm{meq}$ $\mathrm{Ca}^{2+} 100 \mathrm{~g}^{-1}$ đất (Bảng 9).

Bảng 9. Tính chất hóa học của phẫu diện đất phèn nhiễm mặn HD-LN-03 ở mô hình lúa-tôm

\begin{tabular}{|c|c|c|c|c|c|c|c|c|}
\hline \multirow[b]{2}{*}{$\begin{array}{l}\text { Tầng đất } \\
(\mathrm{cm})\end{array}$} & $\mathrm{pH}_{\mathrm{H} 2 \mathrm{O}}$ & $\mathbf{p H}_{\mathrm{KCl}}$ & EC & CEC & $\mathbf{N a}^{+}$ & $\mathbf{K}^{+}$ & $\mathrm{Ca}^{2+}$ & $\mathbf{M g}^{2+}$ \\
\hline & $\begin{array}{r}\text { (Đất:Nước } \\
\sim 1: 5,0) \\
\end{array}$ & $\begin{array}{r}\text { (Đất:KCl } \\
\sim 1: 2,5) \\
\end{array}$ & $\left(\mathrm{mS} \mathrm{cm} \mathrm{cm}^{-1}\right)$ & \multicolumn{5}{|c|}{ (meq $100 \mathrm{~g}^{-1}$ đất) } \\
\hline $0-25$ & 4,38 & 3,22 & 2,30 & 5,47 & 4,17 & 0,56 & 0,68 & 11,0 \\
\hline $25-65$ & 4,60 & 3,80 & 3,80 & 7,31 & 6,56 & 0,96 & 0,90 & 10,2 \\
\hline $65-95$ & 4,20 & 3,07 & 3,00 & 8,22 & 3,96 & 0,98 & 0,83 & 10,8 \\
\hline $95-135$ & 3,56 & 2,76 & 5,50 & 8,44 & 1,17 & 0,70 & 0,54 & 12,3 \\
\hline $135-200$ & 5,74 & 5,31 & 8,00 & 7,34 & 11,26 & 1,18 & 1,11 & 15,6 \\
\hline
\end{tabular}

Hàm lượng đạm tổng số được đánh giá ở mức thấp đối với tầng $0-25,65-95$ và $95-135 \mathrm{~cm}$ với giá trị lần lượt là $0,12,0,13$ và $0,11 \%$, ở hai tầng $25-65$ và $135-200 \mathrm{~cm}$ dao động $0,05-0,09 \%$ được đánh giá ở mức thấp và rất thấp, theo thang đánh giá ở Bảng 1. Mặt khác, hàm lượng đạm hữu dụng ở tầng đất 0 $25 \mathrm{~cm}$ đạt $9,07 \mathrm{mg} \mathrm{NH}{ }^{+} \mathrm{kg}^{-1}$, ở các tầng đất bên dưới có giá trị dao động 5,96-7,34 mg $\mathrm{NH}_{4}{ }^{+} \mathrm{kg}^{-1}$ (Bảng 10).

Bảng 1 cho thấy hàm lượng lân tổng số ở mức thấp, với giá trị là $0,014-0,027 \%$. Ngoài ra, hàm lượng lân dễ tiêu dao động 1,29-9,63 mg $\mathrm{P} \mathrm{kg}^{-1}$ được đánh giá ở mức thấp. Hàm lượng lân nhôm ghi nhận 25,3-30,7 mg P kg-1 hàm lượng lân sắt đạt 11,1-75,8 $\mathrm{mg} \mathrm{P} \mathrm{kg} \mathrm{P}^{-1}$ và hàm lượng lân calcium đạt $10,5-53,9$ mg P kg-1 (Bảng 10).

Bảng 10 cho thấy hàm lượng chất hữu cơ ở các tầng đất canh tác lúa-tôm của phẫu diện HD-LN-03 được đánh giá ở mức rất thấp $(0,20-1,50 \% \mathrm{C})$. Tuy nhiên, đối với tầng đất $25-65 \mathrm{~cm}$ hàm lượng chất hữu cơ đạt 2,84 \% C được đánh giá ở mức thấp, theo thang đánh giá ở Bảng 1 . 
Bảng 10. Độ phì nhiêu của phẫu diện đất phèn nhiễm mặn HD-LN-03 ở mô hình lúa-tôm

\begin{tabular}{|c|c|c|c|c|c|c|c|c|}
\hline \multirow{2}{*}{$\begin{array}{l}\text { Tầng đất } \\
\text { (cm) }\end{array}$} & $\mathrm{N}_{\text {Tổng số }}$ & $\mathrm{NH}_{4}{ }^{+}$ & PTổng số & $\mathbf{P}_{\text {Dễ tiêu }}$ & P-Al & P-Fe & P-Ca & CHC \\
\hline & $(\%)$ & $\left(\mathrm{mg} \mathrm{NH}_{4}{ }^{+} \mathrm{kg}^{-1}\right)$ & $(\% \mathrm{P})$ & \multicolumn{4}{|c|}{$\left.(\mathrm{mg} \mathrm{P} \mathrm{kg})^{-1}\right)$} & $(\% \mathrm{C})$ \\
\hline $0-25$ & 0,12 & 9,07 & 0,014 & 1,93 & 27,1 & 49,4 & 13,9 & 0,20 \\
\hline $25-65$ & 0,09 & 5,96 & 0,027 & 9,63 & 26,2 & 63,9 & 20,7 & 2,84 \\
\hline $65-95$ & 0,13 & 6,30 & 0,016 & 1,29 & 30,7 & 60,5 & 10,5 & 0,90 \\
\hline $95-135$ & 0,11 & 7,34 & 0,016 & 1,29 & 25,3 & 75,8 & 25,0 & 0,65 \\
\hline $135-200$ & 0,05 & 6,78 & 0,025 & 6,42 & 25,8 & 11,1 & 53,9 & 1,50 \\
\hline
\end{tabular}

\section{KẾT LUẬN}

Phẫu diện đất HD-LN-01 thuộc đất phèn tiềm tàng xuất hiện rất sâu, nhiễm mặn trong khi phẫu diện đất HD-LN-02 và HD-LN-03 được phân loại là đất phèn hoạt động xuất hiện sâu, nhiễm mặn trong hệ thống tôm-lúa tại xã Lộc Ninh, huyện Hồng Dân, tỉnh Bạc Liêu.

Giá trị $\mathrm{pH}_{\mathrm{H} 2 \mathrm{O}}$ và $\mathrm{pH} \mathrm{KCl}_{\mathrm{C}}$ tầng đất mặt có giá trị lần lượt dao động 4,38-5,28 và 3,22-4,43. Hàm lượng đạm tổng số và lân tổng số trong các tầng đất được đánh giá ở mức nghèo. Hàm lượng đạm hữu dụng đối với cả ba phẫu diện dao động 1,33-9,07 mg NH${ }_{4}^{+}$ $\mathrm{kg}^{-1}$ và hàm lượng lân dễ tiêu đạt giá trị 1,29-19,24 $\mathrm{mg} \mathrm{P} \mathrm{kg}{ }^{-1}$ được đánh giá ở mức thấp. Ngoài ra, hàm lượng lân khó tan bao gồm hàm lượng lân nhôm đạt 14,6-45,9 mg $\mathrm{P} \mathrm{kg}^{-1}$, hàm lượng lân sắt được xác định $11,1-84,3 \mathrm{mg} \mathrm{P} \mathrm{kg}^{-1}$ và lân calcium đạt giá trị $10,5-111,0 \mathrm{mg} \mathrm{P} \mathrm{kg}^{-1}$. Hàm lượng $\mathrm{Na}^{+}$trao đồi dao động 4,17-4,99 meq $\mathrm{Na}^{+} 100 \mathrm{~g}^{-1}$ dất. Hàm lượng chất hữu cơ được đánh giá ở mức rất thấp đến thấp.

\section{TÀI LIỆU THAM KHẢO}

Be, T. T., Dung, L. C., \& Brennan, D. (1999). Environmental costs of shrimp culture in the rice-growing regions of the Mekong Delta. Aquaculture Economics \& Management, 3(1), 31-42.

FAO. (1977). Guidelines for Soil Profile Description ( $2^{\text {nd }}$ ed.). Soil Resources Development and Conservation Service, Land and Water Development Division, FAO, Rome. Grassi, F., Paris, T. R., \& Truong, T. N. C. (2017). Rice-rice and rice-shrimp production: A gender perspective on labour, time use and access to technologies and services in southern Viet Nam. FAO.

Jahn, R., Blume, H. P., Asio, V. B., Spaargaren, O., \& Schad, P. (2006). Guidelines for soil description. FAO.

Horneck, D. A., Sullivan, D. M., Owen, J. S., \& Hart J. M. (2011). Soil test interpretation guide. EC
1478. Corvallis, OR: Oregon State University Extension Service. Pp:1-12.

Landon, J. R., (1984). Booker tropical soil manual: a handbookfor soil survey and agricultural land evaluation in the tropics and subtropics. Longman Inc.: New York.

Lê Văn Dang \& Ngô Ngọc Hưng. (2018). Ảnh hưởng của hệ sinh thái ngọt và lợ đến sinh trưởng lúa và đặc tính hoá học đất trong hệ thống canh tác lúa - tôm ở tỉnh Bạc Liêu. Tạp chí Khoa hoc Nông nghiệp Việt Nam, 16(5), 481-490.

Metson A. J. (1961). Methods of chemical analysis of soil survey samples. Govt. Printers, Wellington, New Zealand.

Nguyễn Quốc Khương \& Ngô Ngọc Hưng. (2015a). Đánh giá đặc tính đất lúa - tôm bị nhiễm mặn ở các vùng sinh thái thuộc tỉnh Bạc Liêu. Tạp chí Nông nghiệp và phát triển nông thôn, 3+4, 108-115.

Nguyễn Quốc Khương \& Ngô Ngọc Hưng. (2015b). Đặc tính mặn đất lúa trong mô hình lúa tôm tại tỉnh Cà Mau. 2015. Tạp chí Khoa hoc đất, 45, 104-110.

Nguyễn Xuân Cự. (2000). Đánh giá khả năng cung cấp và xác định nhu cầu dinh dưỡng phốt pho cho cây lúa nước trên đất phù sa sông Hồng. Thông báo Khoa hoc của các trưòng Đại học, Bộ Giáo duc và Đào tạo - phần Khoa học Môi trường, Hà Nọi, 162 - 170.

Schad, P., \& Spaargaren, O. (2006). World reference base for soil resources 2006: A framework for international classification, correlation and communication. Food and agriculture organization of the United nations (FAO).

Bremner, J. M., \& Sparks, D. L. (1996). Methods of soil analysis. Part 3. Chemical methods. Soil Science Society of America, Madison, WI, 1103e1108.

Tho, N., Vromant, N., Hung, N. T., \& Hens, L. (2008). Soil salinity and sodicity in a shrimp farming coastal area of the Mekong Delta, Vietnam. Environmental Geology, 54(8), 1739-1746.

Tuan, P. A., Hai T.N., Tu, T.Q. (2016). Development of rice-shrimp farming in Mekong River Delta. Vietnam 54. 